\title{
1,3-Adamantanedicarboxylate and 1,3-Adamantanediacetate as Uranyl Ion Linkers: Effect of Counterions, Solvents and Differences in Flexibility
}

\author{
Pierre Thuéry, ${ }^{*[a]}$ Youssef Atoini ${ }^{[b]}$ and Jack Harrowfield*[b] \\ ${ }^{[a]}$ NIMBE, CEA, CNRS, Université Paris-Saclay, CEA Saclay, 91191 Gif-sur-Yvette, France \\ E-mail: pierre.thuery@cea.fr \\ http://iramis.cea.fr/nimbe/ \\ ${ }^{[b]}$ ISIS, Université de Strasbourg, 8 allée Gaspard Monge, 67083 Strasbourg, France \\ E-mail: harrowfield@unistra.fr \\ https://isis.unistra.fr/fr/
}

Keywords: Uranium(VI) / Carboxylic acids / Structure elucidation / Coordination networks

\begin{abstract}
Seven homo- or heterometallic uranyl ion complexes with 1,3-adamantanedicarboxylic acid $\left(\mathrm{H}_{2} \mathrm{ADC}\right)$ or 1,3-adamantanediacetic acid $\left(\mathrm{H}_{2} \mathrm{ADA}\right)$ have been synthesized under solvo-hydrothermal conditions in the presence of different counterions and organic cosolvents, and characterized by their crystal structure and uranyl emission spectrum. $\left[\mathrm{PPh}_{3} \mathrm{Me}\right]\left[\mathrm{UO}_{2}(\mathrm{ADC})\left(\mathrm{NO}_{3}\right)\right](\mathbf{1})$ crystallizes as a simple monoperiodic chain, but $\left[\mathrm{PPh}_{4}\right]_{2}\left[\left(\mathrm{UO}_{2}\right)_{2}(\mathrm{ADC})_{3}\right] \cdot 2 \mathrm{H}_{2} \mathrm{O}(2)$ and $\left[\mathrm{PPh}_{4}\right]_{2}\left[\left(\mathrm{UO}_{2}\right)_{2}(\mathrm{ADA})_{3}\right](3)$ display trough-like monoperiodic assemblies (assembled in pairs in $\mathbf{3}$ ) in the cavity of which the counterions are located. A similar arrangement is found in $\left[\mathrm{Ni}(\mathrm{cyclen})\left(\mathrm{H}_{2} \mathrm{O}\right)\right]\left[\left(\mathrm{UO}_{2}\right)_{2}(\mathrm{ADC})_{3}\right] \cdot \mathrm{H}_{2} \mathrm{O}$ (4). Diaxial bonding of $\mathrm{Ni}$ in $\left[\left(\mathrm{UO}_{2}\right)_{2}(\mathrm{ADC})_{2} \mathrm{Ni}\left(R, S-\mathrm{Me}_{6} \mathrm{Cyclam}\right)(\mathrm{HCOO})_{2}\right] \cdot \mathrm{CH}_{3} \mathrm{CN}$ (5) and $\left[\mathrm{UO}_{2}(\mathrm{ADA})_{2} \mathrm{Ni}\left(R, S-\mathrm{Me}_{6} \mathrm{Cyclam}\right)\right]$ (6) results in bridging monoperiodic uranyl-containing subunits into neutral, diperiodic networks. [ $\left.\mathrm{UO}_{2}(A D A)(D M P U)\right]$ (7), containing coordinated $N, N^{\prime}$-dimethylpropyleneurea, is also a diperiodic assembly with the common fes topological type. Except complex $\mathbf{6}$ which is non-luminescent, all complexes give solid-state emission spectra displaying the usual vibronic fine structure, albeit with low photoluminescence quantum yields.
\end{abstract}




\section{Introduction}

1,3-Adamantanedicarboxylate $\left(\mathrm{ADC}^{2-}\right)$ and 1,3-adamantanediacetate $\left(\mathrm{ADA}^{2-}\right)$ are two closely related ligands, both possessing the rigid and bulky adamantyl skeleton and differing by the larger breadth and higher flexibility of the latter. Although both ligands are rather common in coordination chemistry generally, with 135 and 95 examples of structures containing $A D C^{2-}$ and $A D A^{2-}$, respectively, reported in the Cambridge Structural Database (CSD, version $5.40^{[1]}$ ), their use in uranyl coordination chemistry, and in particular in the design of uranyl-organic coordination polymers and frameworks, ${ }^{[2]}$ is quite recent, and only 12 and 10 crystal structures are known for $A D C^{2-}$ and $A D A^{2-}$, respectively ${ }^{[3-7]}$ (concerning the larger class of actinide complexes, only two additional thorium(IV) complexes are known $\left.{ }^{[8]}\right) . A D C^{2-}$ has been shown to give mono-, di- or triperiodic (denoted 1D, 2D and 3D for convenience) homo- or heterometallic uranyl-containing coordination polymers, ${ }^{[3,4,6]}$ the $3 \mathrm{D}$ species being of particular interest in the context of the search for cavity-containing structures possibly suited to application as selective photocatalysts. However, the case of $\mathrm{ADA}^{2-}$ appeared to be perhaps of greater interest since, apart from $1 D$ and $2 D$ assemblies, ${ }^{[5-7]}$ this ligand has provided discrete tetranuclear metallatricycles defining an incompletely occupied space when mixtures of $\mathrm{NH}_{4}^{+}$and either $\mathrm{PPh}_{3} \mathrm{Me}^{+}$or $\mathrm{PPh}_{4}{ }^{+}$are used as counterions. ${ }^{[7]}$ The formation of these $\left[\left(\mathrm{UO}_{2}\right)_{4}(\mathrm{ADA})_{6}\right]^{4-}$ anionic species exploits the variable geometry of $\mathrm{ADA}^{2-}$ since two 2:2 rings built from the convergent form of the ligand are assembled together by two additional ligands in their extended, divergent conformation. The counterions probably exert a structure-directing effect, $\mathrm{NH}_{4}{ }^{+}$being linked to the small 2:2 rings through triple hydrogen bonding, whereas $\mathrm{PPh}_{3} \mathrm{Me}^{+}$or $\mathrm{PPh}_{4}{ }^{+}$face the larger 
ring. In seeking to further unravel the multiplicity of influences affecting the formation of closed uranyl-polycarboxylate oligomers through comparisons of $\mathrm{ADC}^{2-}$ and $\mathrm{ADA}^{2-}$ complexes, we investigated the formation of anionic complexes of these ligands in the presence of diverse bulky counterions displaying a range of possible interactions with the anionic complex, $\mathrm{PPh}_{3} \mathrm{Me}^{+}$or $\mathrm{PPh}_{4}{ }^{+}$(in the absence of $\mathrm{NH}_{4}{ }^{+}$), $\left[\mathrm{Ni}(\text { cyclen) }]^{2+}\right.$ (cyclen $=1,4,7,10$-tetraazacyclododecane), and $\left[\mathrm{Ni}\left(R, S-\mathrm{Me}_{6} \mathrm{Cyclam}\right)\right]^{2+} \quad\left(R, S-\mathrm{Me}_{6} \mathrm{Cyclam} \quad=\quad 7(R), 14(S)-5,5,7,12,12,14\right.$-hexamethyl-1,4,8,11tetraazacyclotetradecane, meso isomer). A neutral uranyl complex with ADA $^{2-}$ involving DMPU $\left(N, N^{\prime}\right.$-dimethylpropyleneurea) as additional ligand has also been obtained, and all seven complexes have been characterized by their crystal structure and emission spectrum in the solid state.

\section{Results and Discussion}

\section{Syntheses}

All seven complexes were synthesized under solvo-hydrothermal conditions $\left(140{ }^{\circ} \mathrm{C}\right.$, autogenous pressure), with either a single organic cosolvent (DMF for 3, DMPU for 7), or a mixture of organic cosolvents $\left(\mathrm{CH}_{3} \mathrm{CN} / \mathrm{THF}\right.$ for $\mathbf{1}$, DMF/THF for 2, and $\mathrm{CH}_{3} \mathrm{CN} / \mathrm{DMF}$ for 4-6). The organic cosolvent is retained in the final compound only in the cases of DMPU, which is coordinated to the uranyl cation in complex 7, and of $\mathrm{CH}_{3} \mathrm{CN}$ in the solvate $\mathbf{5}$. However, the formate anions present in $\mathbf{5}$ are presumed to have been generated in situ from DMF hydrolysis. In order to promote the formation of anionic uranyl complexes and thus ensure the incorporation of counterions, the uranium/dicarboxylate ligand ratio in the syntheses of 1-6 was 7:10, and the expected 2:3 ratio in the final compound is found indeed for complexes $\mathbf{2 - 4}$, while the ratio is $\mathbf{1 : 1}$ in $\mathbf{1}$ and $\mathbf{5}$ (with 
extra nitrato or formato ligands, respectively), and 1:2 in $\mathbf{6}$. These results provide yet further illustration of the somewhat capricious nature of syntheses involving labile metal ions and depending upon product crystallization, as well as the need to carefully consider the full nature of any reaction mixture and what may happen to its components during the reaction period. It is difficult to know what influence the solvent mixture, regardless of any reactions of its components, may have had upon the nature of the crystalline product species, as these mixtures were developed solely as a means of ensuring rapid initial formation of a homogeneous solution of the reactants.

\section{Crystal Structures}

Two complexes were obtained with $\mathrm{ADC}^{2-}$ in the presence of phosphonium cations, $\left[\mathrm{PPh}_{3} \mathrm{Me}\right]\left[\mathrm{UO}_{2}(\mathrm{ADC})\left(\mathrm{NO}_{3}\right)\right](1)$ and $\left[\mathrm{PPh}_{4}\right]_{2}\left[\left(\mathrm{UO}_{2}\right)_{2}(\mathrm{ADC})_{3}\right] \cdot 2 \mathrm{H}_{2} \mathrm{O}(2)$. A chelating nitrate ligand is present in 1 , the uranyl cation only being further chelated in $\kappa^{2} O, O^{\prime}$ mode by two carboxylate groups, the hexagonal bipyramidal uranium environment having usual bond lengths [ $\mathrm{U}-\mathrm{O}$ (oxo) $1.763(3)$ and $1.770(3) \AA$, U-O(carboxylato) $2.425(3)-2.450(3) \AA$, U-O(nitrato) $2.525(3)$ and $2.540(3) \AA ̊$ ] (Figure 1). Nitrate chelation has been found in the product of various syntheses similar to those of the present work but in general it appears to compete ineffectively with that of carboxylate. In 1, a simple, gently undulating 1D coordination polymer parallel to [101] is formed, with the nitrate and carboxylate anions oriented toward opposite edges, and the adamantyl groups protruding alternately up and down. These chains are arranged in layers parallel to (010), separated from one another by layers of counterions. A P...P distance of 8.336(2) $\AA$ within the layers is possibly indicative of the formation of centrosymmetric pairs through a parallel 

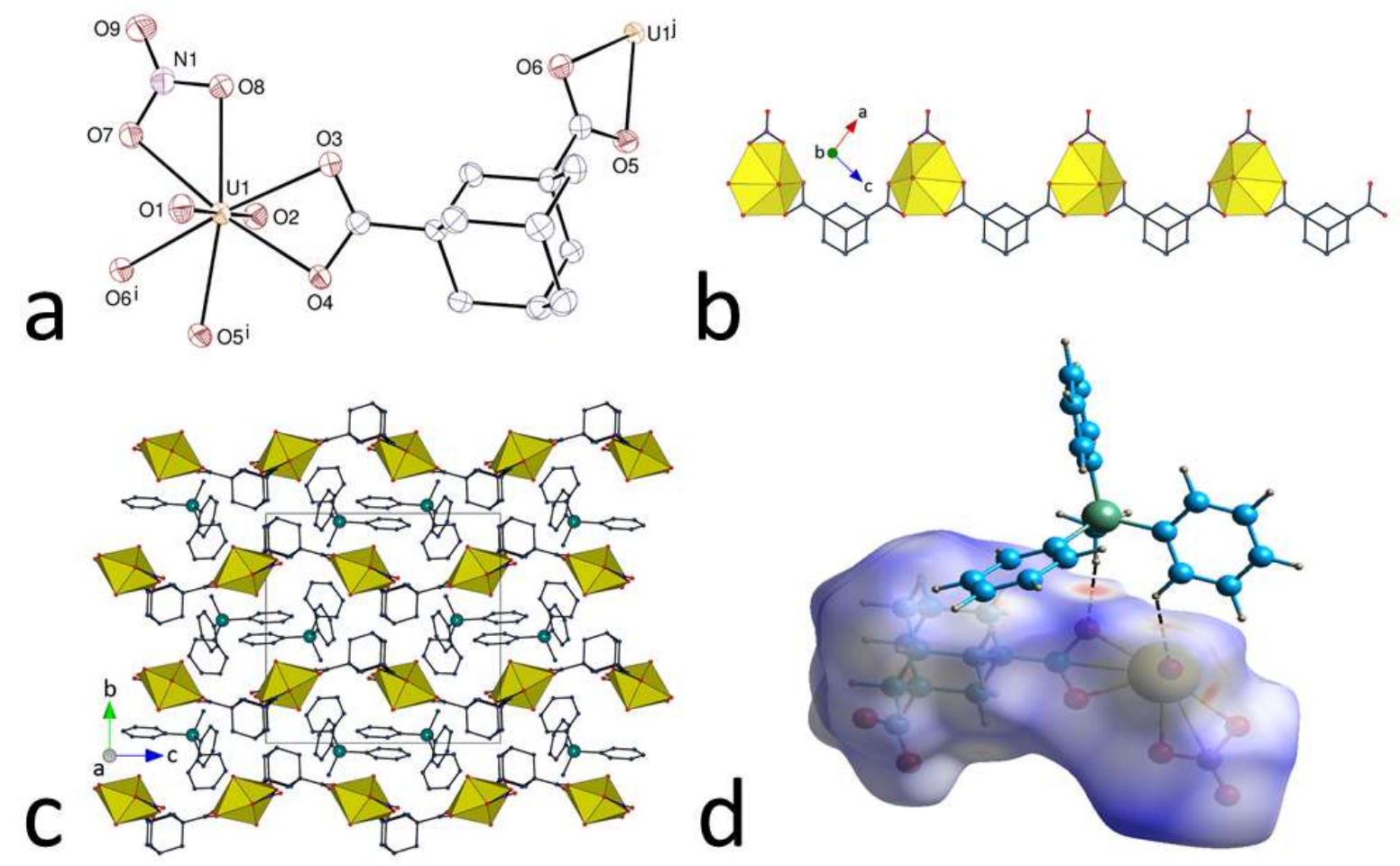

Figure 1. (a) View of complex 1. Displacement ellipsoids are drawn at the 50\% probability level, and counterions and hydrogen atoms are omitted. Symmetry codes: $\mathrm{i}=x-1 / 2,1 / 2-y, z-1 / 2 ; \mathrm{j}=x+$ $1 / 2,1 / 2-y, z+1 / 2$. (b) View of the $1 \mathrm{D}$ coordination polymer with uranium coordination polyhedra colored yellow. (c) Packing with chains viewed sideways and hydrogen atoms omitted. (d) Hirshfeld surface mapped with $d_{\text {norm }}$ calculated on the anionic part of the asymmetric unit. The red spots correspond to the positions of $\mathrm{CH} \cdots \mathrm{O}$ hydrogen bonds (dashed lines).

quadruple phenyl embrace, both the distance and the positioning of the aromatic rings being typical of such interactions; ${ }^{[9]}$ there is an even shorter interlayer P...P distance of $7.9618(8) \AA$, which is not associated with such a well-defined juxtaposition and there is no short contact indicative of significant $\pi$-stacking interactions. As usual in uranyl carboxylate complexes involving phosphonium counterions, several $\mathrm{CH} \cdots \mathrm{O}$ hydrogen bonding interactions ${ }^{[10]}$ are present, which 
involve either the methyl group and carboxylate or nitrate oxygen atoms, or aromatic protons and the uranyl oxo atom 01 [C $\cdots .0$ distances $3.255(5)-3.383(5) \AA, C-H \cdots O$ angles $\left.135-164^{\circ}\right]$, and one reason for the presence of nitrate in the structure may be its interaction with the phosphonium methyl group. These interactions appear prominently on the Hirshfeld surface $(\mathrm{HS})^{[11]}$ calculated on the asymmetric unit with CrystalExplorer, ${ }^{[12]}$ the red dots in Figure $1(\mathrm{~d})$ corresponding to contacts shorter than the sum of van der Waals radii. With a Kitaigorodski packing index ( $\mathrm{KPI}$, estimated with PLATON ${ }^{[13]}$ ) of $\sim 0.67$, the packing in 1 does not contain solventaccessible spaces.

Complex 2 crystallizes in the monoclinic Sohncke group P2 ${ }_{1}$, and the two independent uranyl cations are both tris-chelated by three carboxylate groups [U-O(oxo) $1.749(7)-1.780(7) \AA$, U-O(carboxylato) 2.434(6)-2.513(6) Å] (Figure 2). The 1D coordination polymer formed, parallel to [100], is here ladderlike, the uranium atoms being threefold nodes, and the double-stranded polymer entities involve fused 32-membered metallacycles and have a trough-like form with a Vshaped section, into which both water molecules and half the phosphonium cations intrude. The limitation of the rotational freedom of the ligand to that about the $\mathrm{C}-\mathrm{CO}_{2}$ bond is apparent in the fact that the two independent but virtually identical ligands which line the edges of the trough have C-C-C-O torsion angle pairs of $16.5(14) / 10.3(16)^{\circ}$ and $19.0(13) / 17.1(13)^{\circ}$, while the ligand bridging these strands has much larger values of $87.8(11) / 91.8(11)^{\circ}$. It is this unique, cross-linking ligand that imposes a degree of curvature on the polymer and provides its trough-like form. An influence of hydrogen bonding is still apparent in that, as shown in Figure 2(d), $\left(\mathrm{H}_{2} \mathrm{O}\right)_{2}$ units are triple hydrogen bond donors linking carboxylate oxygen atoms bound to $U 2$ only (a fourth hydrogen bond linking 

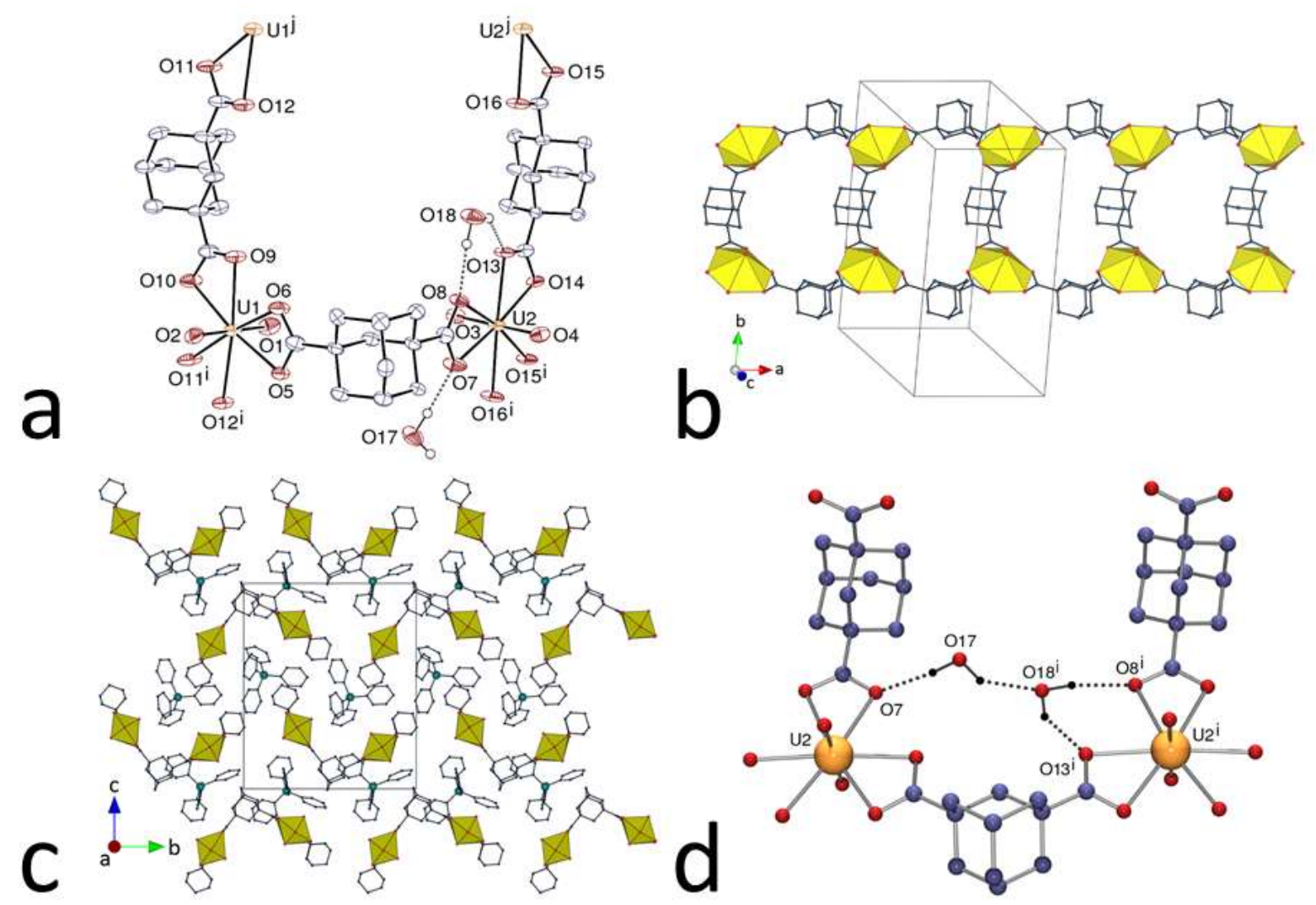

Figure 2. (a) View of complex 2. Displacement ellipsoids are drawn at the $50 \%$ probability level. Carbon-bound hydrogen atoms and counterions are omitted, and hydrogen bonds are shown as dashed lines. Symmetry codes: $\mathrm{i}=$ $x+1, y, z ; j=x-1, y, z$. (b) View of the 1D coordination polymer with uranium coordination polyhedra colored yellow. (c) Packing with chains viewed end-on. (d) Hydrogen bonding of the water molecules along a polymer strand.

the two water molecules), thus rendering the two edges of the trough inequivalent $[0 \cdots 0$ distances 2.832(9)-2.953(9) $\AA, \mathrm{O}-\mathrm{H} \cdots \mathrm{O}$ angles $\left.138-171^{\circ}\right]$. There is thus formation of two hydrogen bonding rings, corresponding to the graph set descriptors ${ }^{[14]} R_{2}^{2}(6)$ and $R_{3}^{3}(14)$. The water molecule containing $\mathrm{O} 17$ and involved in only one hydrogen bond interaction with a carboxylato group is an

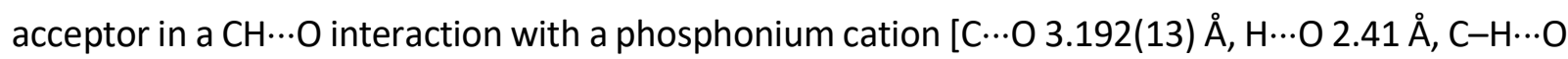
$139^{\circ}$ ] which might be considered to draw this phosphonium (incorporating P2) into the trough, although the cation is involved in other interactions (predominantly $\mathrm{CH} \cdots \mathrm{O}$ ) which serve to bridge 
polymer units, together with $\mathrm{CH} \cdots \mathrm{O}$ interactions of the phosphonium cation incorporating $\mathrm{P} 1$. The 1D polymers are here also arranged in layers parallel to (001), separated by layers of cations. The unsymmetrical nature of the polymer units in fact renders them chiral and can be considered the basis of the formation of the chiral crystal. No P...P distance is shorter than $9 \AA$, and the packing (KPI 0.66) seems to be governed here by cation-anion interactions only and not by phenyl embrace interactions.

The analogue of 2 with the $A D A^{2-}$ ligand, $\left[\mathrm{PPh}_{4}\right]_{2}\left[\left(\mathrm{UO}_{2}\right)_{2}(\mathrm{ADA})_{3}\right](\mathbf{3})$, is not isomorphous with $\mathbf{2}$ and crystallizes in the triclinic system, the crystal being achiral. Here also, the two uranium atoms are tris-chelated [U-O(oxo) 1.7642(19)-1.779(3) $\AA, \mathrm{U}-\mathrm{O}$ (carboxylato) $2.435(2)-2.490(2) \AA]$ (Figure 3). The 1D polymer formed, parallel to [100], is analogous to that in $\mathbf{2}$ but for a much flatter shape due to the extended conformation of the central ligand. A difference however is that there is no formation in $\mathbf{3}$ of alternate sheets of cations and anions, but instead centrosymmetric couples of 1D polymers facing each other through their shallow concave side and surrounding doubles columns of cations can be discerned, as shown in Figure 3(c) (other columns of cations being located between these dimers). The three inequivalent ligand units all adopt chiral conformations, those of the flanking species having close to $C_{2}$ symmetry. The shortest $\mathrm{P} \ldots \mathrm{P}$ distance of 7.7791(18) $\AA$ is between inversion-related phosphonium ions within the $1 \mathrm{D}$ dimer, and could be considered to be associated with one face-to-face interaction between aromatic rings but for the long centroid...centroid distance of $5.032(2) \AA$, so that the presence of a significant interaction is doubtful. The HS surfaces show only $\mathrm{CH} \cdots \mathrm{O}$ interactions, as usual, and the $\mathrm{KPI}$ amounts to 0.66 . The most interesting point with this structure is its difference with that of $\left[\mathrm{NH}_{4}\right]_{2}\left[\mathrm{PPh}_{4}\right]_{2}\left[\left(\mathrm{UO}_{2}\right)_{4}(\mathrm{ADA})_{6}\right]$, which crystallizes as a discrete, tetranuclear metallatricycle. ${ }^{[7]}$ 

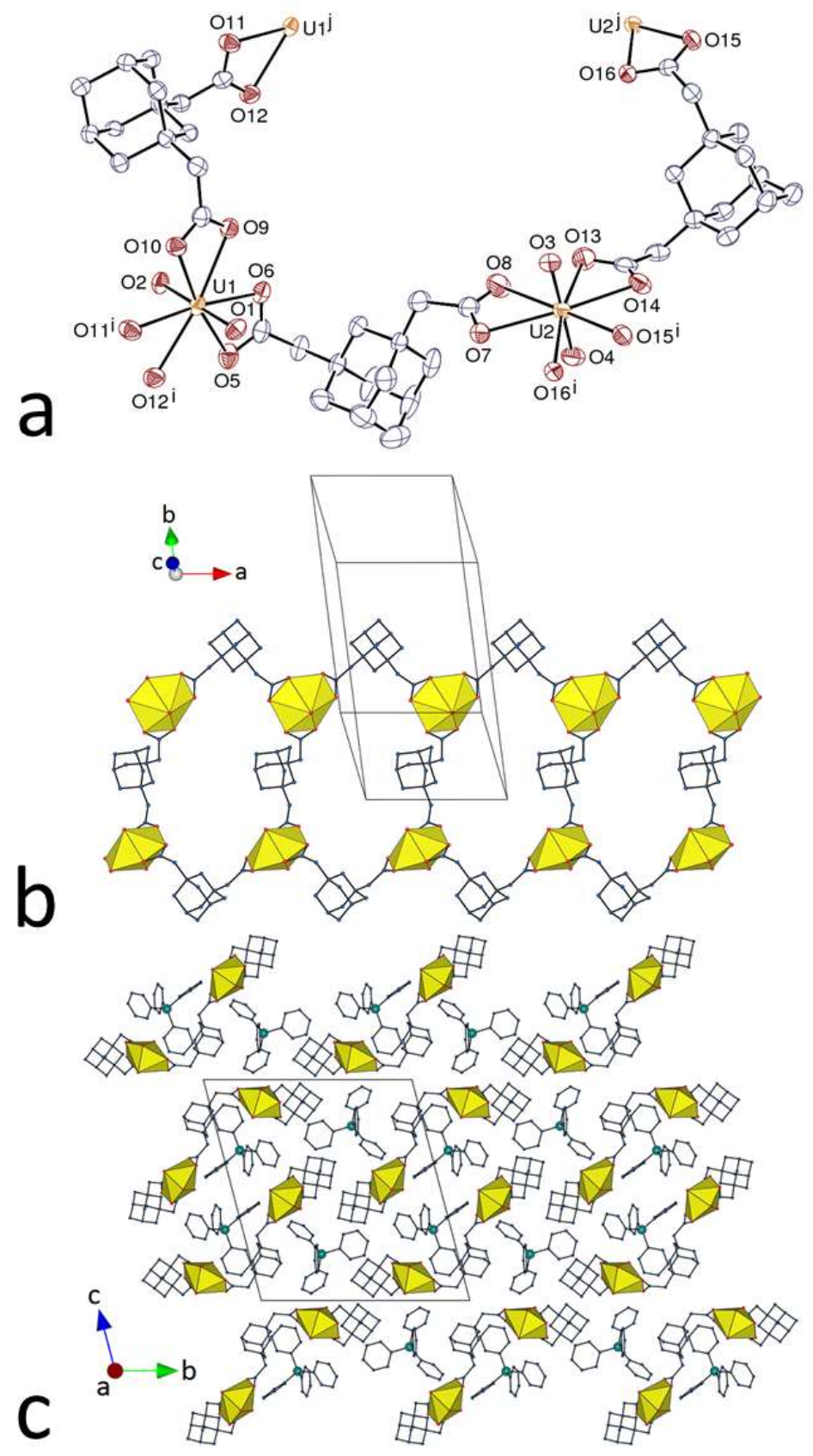

Figure 3. (a) View of complex 3. Displacement ellipsoids are drawn at the $50 \%$ probability level, and counterions are omitted. Symmetry codes: $\mathrm{i}=x+1, y, z ; \mathrm{j}=x-1, y, z$. (b) View of the $1 \mathrm{D}$ coordination polymer with uranium coordination polyhedra colored yellow. (c) Packing with chains viewed end-on. Hydrogen atoms are omitted in all views. 
Both complexes have the same uranyl/ADA ${ }^{2-}$ 2:3 ratio and they differ by replacement of half the $\mathrm{PPh}_{4}{ }^{+}$cations in 3 by ammonium cations generated in situ from acetonitrile hydrolysis (the synthesis of 3 involving only DMF as organic cosolvent). This points to the essential role of $\mathrm{NH}_{4}^{+}$ cations in the formation of the closed species. More generally, due to its small size and involvement in multiple hydrogen bonding with acceptor groups which are necessarily rather close to one another, this cation appears to be particularly well suited to the formation of closed uranyl carboxylate species, as seen in the last cited complex but also in the cases of tetranuclear clusters $^{[15]}$ and octanuclear cages ${ }^{[16]}$ involving trans- and cis-1,2-cyclohexanedicarboxylate ligands, respectively, and of tubelike assemblies containing tricarballylate ligands. ${ }^{[17]}$ A paradox, however is that syntheses performed in the presence of ammonium cations added in stoichiometric quantity have invariably failed to produce the same product, and slow generation of the cation through hydrolysis of acetonitrile used as a cosolvent appears, somewhat unexpectedly, to be a more efficient way of introducing it.

The complex $\left[\mathrm{Ni}(\right.$ cyclen $\left.)\left(\mathrm{H}_{2} \mathrm{O}\right)\right]\left[\left(\mathrm{UO}_{2}\right)_{2}(\mathrm{ADC})_{3}\right] \cdot \mathrm{H}_{2} \mathrm{O} \quad(4)$ is another example of a heterometallic uranyl complex with $\mathrm{ADC}^{2-}$, after several others containing transition metal cations bound to 2,2'-bipyridine and either included in the coordination polymer or present as counterions. ${ }^{[4]}$ While the ligand cyclen has been found, in its tetraprotonated form, as a guest in the remarkable closed octanuclear cluster formed by tetracarboxylatocalix[4]arene with uranyl ion, ${ }^{[18]}$ our attempts to use its metal ion complexes as structure-directing agents in uranyl complex formation have so far met with limited success. The two independent uranium atoms in 4 are both tris-chelated by carboxylate groups [U-O(oxo) 1.766(8)-1.780(7) $\AA$, U-O(carboxylato) 2.434(5)-2.490(5) Å] (Figure 4). The $\left[\mathrm{Ni}\left(\text { cyclen) }\left(\mathrm{H}_{2} \mathrm{O}\right)\right]^{2+}\right.$ counterion is highly disordered over a 


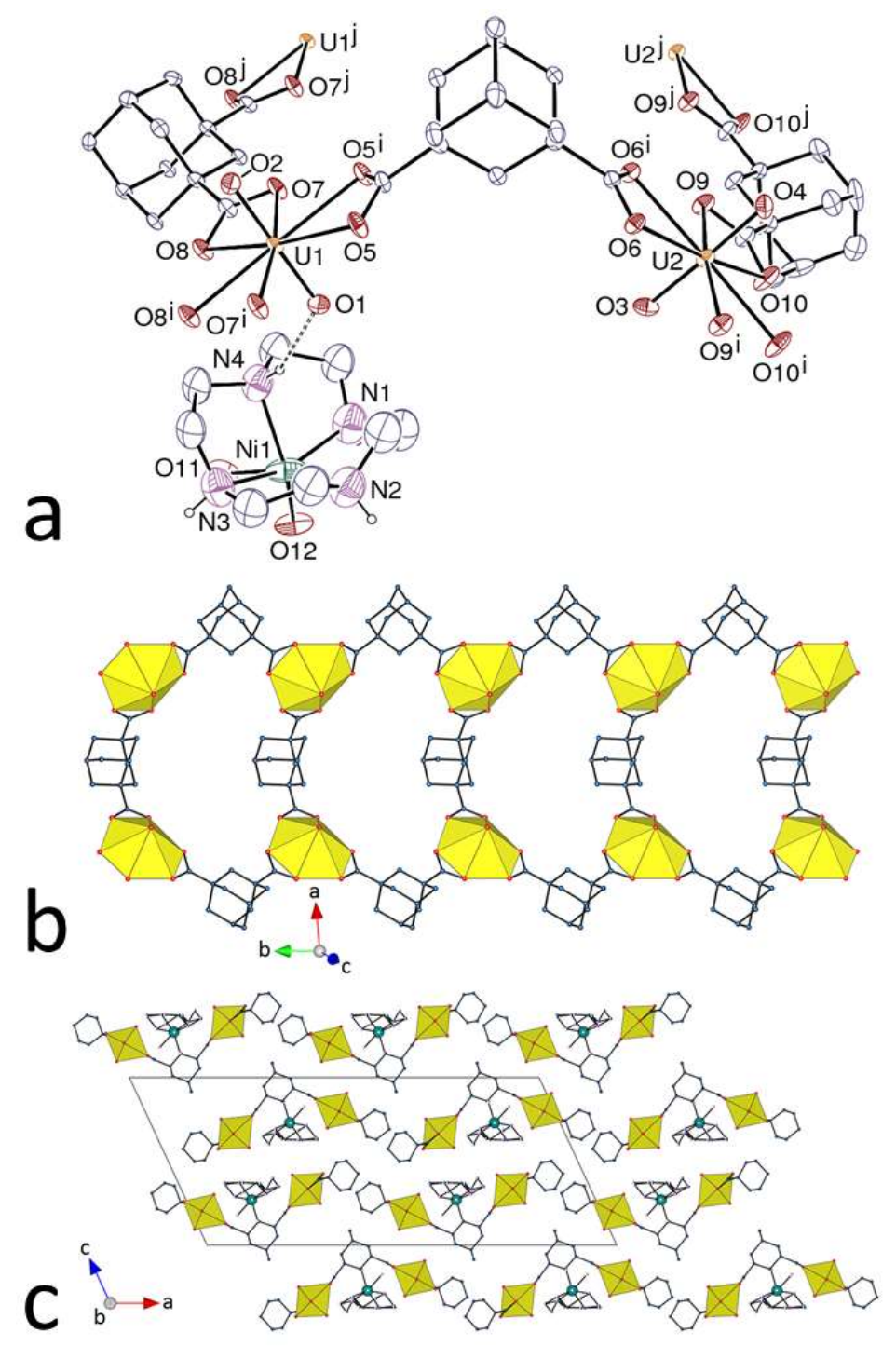

Figure 4. (a) View of complex 4. Displacement ellipsoids are drawn at the $20 \%$ probability level. The solvent molecule and carbon-bound hydrogen atoms are omitted, and the hydrogen bond is shown as a dashed line. Only one position of the disordered cyclen moiety is represented. Symmetry codes: $\mathrm{i}=x, 1-y, z ; \mathrm{j}=x, 2-y, z$. (b) View of the 1D coordination polymer with uranium coordination polyhedra colored yellow. (c) Packing with chains viewed end-on.

plane of symmetry (see Experimental Section). Only one disordered water molecule could be refined, so that the composition is that of the intermediate considered to be involved in the conversion of octahedral $\left[\mathrm{Ni}(\text { cyclen })\left(\mathrm{H}_{2} \mathrm{O}\right)_{2}\right]^{2+}$ to square-planar $[\mathrm{Ni}(\text { cyclen })]^{2+}{ }^{219]}$ A possibility 
would be the coexistence of the two forms, both disordered, but the moderate quality of the data did not allow their separation. Unlike cyclam (1,4,8,11-tetraazacyclotetradecane) cyclen is a ligand which does not adopt preferentially a configuration in which its four nitrogen donor atoms lie in a plane about a metal cation of the first transition metal series, as seen, for example, in the complex [Ni(cyclen) $\left.\left(\mathrm{CH}_{3} \mathrm{CO}_{2}\right)\right] \mathrm{BF}_{4} \cdot{ }^{[20]}$ Hence, the behaviour of its $\mathrm{Nil}$ complex as an hydrogen bond donor and potential coordinating unit in uranyl complex structures was expected to differ significantly from what is observed with complexes of cyclam or R,S-Me6cyclam (see below). What is seen in complex $\mathbf{4}$ is that the uranyl-carboxylate unit is a double-stranded $1 \mathrm{D}$ polymer parallel to [010], of a trough-like form very similar to that seen in complexes $\mathbf{2}$ and $\mathbf{3}$. The trough profile is shallower than that of $\mathbf{2}$ but also close to symmetrical (unlike that of $\mathbf{3}$ ), with the $\mathrm{Nill}$ complex units lying more nearly completely within the trough than do the $\mathrm{PPh}_{4}{ }^{+}$units in $\mathbf{2}$. Here also, 1D chains are facing one another in slightly offset pairs related by twofold rotation, and the cations are located in between. Disorder in the $\left[\mathrm{Ni}(\text { cyclen })\left(\mathrm{H}_{2} \mathrm{O}\right)\right]^{2+}$ cations renders analysis of their interactions with the polymer somewhat uncertain but it is clear that there is no direct coordination and that although hydrogen bonds with oxo and carboxylato groups of both 1D units of the pair may be present, $\mathrm{NH} \cdots \mathrm{O}$ separations are too large for any interactions to be considered strong. Some $\mathrm{CH} \cdots \mathrm{O}$ separations, however, are sufficiently short for interaction greater than dispersion to be possible.

Replacement of cyclen by $R, S-\mathrm{Me}_{6}$ cyclam yields the complex $\left[\left(\mathrm{UO}_{2}\right)_{2}(\mathrm{ADC})_{2} \mathrm{Ni}(R, S-\right.$ $\left.\left.\mathrm{Me}_{6} \mathrm{cyclam}\right)(\mathrm{HCOO})_{2}\right] \cdot \mathrm{CH}_{3} \mathrm{CN}$ (5), which includes formato ligands generated in situ from DMF hydrolysis. The unique uranium atom is chelated by only one carboxylate group from $\mathrm{ADC}^{2-}$, and is bound to two more oxygen donors from two $\mathrm{ADC}^{2-}$ anions and one from formate [U-O(oxo) 
$1.7683(19)$ and $1.7723(19) \AA, \mathrm{U}-\mathrm{O}$ (carboxylato) $2.4275(18)$ and $2.4917(19) \AA$ for the chelating group, and 2.316(2)-2.3787(16) ^̊ for the other carboxylate donors] (Figure 5). The nickel(II)
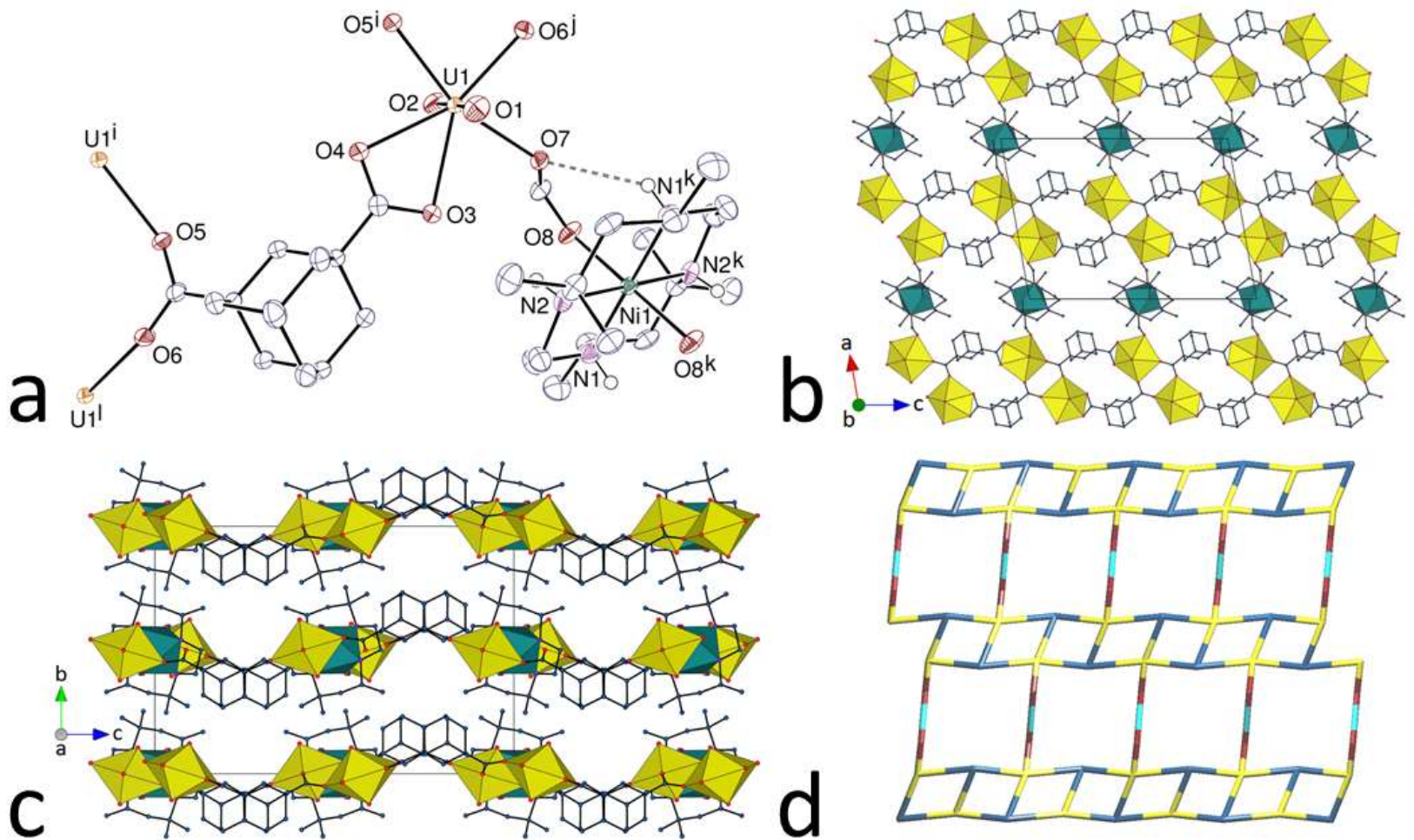

Figure 5. (a) View of complex 5. Displacement ellipsoids are drawn at the $50 \%$ probability level. The solvent molecule and carbon-bound hydrogen atoms are omitted, and the hydrogen bond is shown as a dashed line. Symmetry codes: $\mathrm{i}=-x, y, 1 / 2-z ; \mathrm{j}=x, 1-y, z+1 / 2 ; \mathrm{k}=1-x, 1-y, 1-z ; \mathrm{I}=x, 1-y, z-1 / 2$. (b) View of the 2D network with uranium coordination polyhedra colored yellow and those of nickel(II) green. (c) Packing with layers viewed edge-on. (d) Nodal representation of the network (yellow: uranium nodes, dark blue: $A D C^{2-}$ nodes, light blue: nickel(II) links, dark red: formate links), same orientation as in (b).

cation, located on an inversion centre, is bound to the four nitrogen atoms of the macrocycle and two axial formato ligands [Ni-N 2.071(2) and 2.102(2) $\AA$, Ni-O 2.1203(17) $\AA$ ], its environment being thus octahedral. The macrocycle is in the usual trans-III conformation and the nitrogen donors adopt the $R, S, R, S$ configurations. ${ }^{[21]}$ Uranium is thus a fourfold node and the $A D C^{2-}$ ligand 
a threefold node, being bound in $\kappa^{2} O, O^{\prime} / \mu_{2}-\kappa^{1} O: \kappa^{1} O^{\prime}$ mode, while nickel(II) and formate are simple links in the 2D assembly formed. This network is parallel to (010) and it has the point symbol $\left\{4^{2} .6^{3} .8\right\}\left\{4^{2} .6\right\}$ and the $\mathbf{V}_{\mathbf{2}} \mathbf{O}_{\mathbf{5}}$ topological type. This topology was previously found in other heterometallic uranyl ion complexes, involving tetrahydrofurantetracarboxylate, pimelate and 1,2,3,4-cyclobutanetetracarboxylate ligands. ${ }^{[22]}$ However the roles of uranyl and polycarboxylate ligand as three- and fourfold nodes are exchanged here with respect to the three previous cases, due to the difference in the nature of the links (simple metal cations in the other cases, and formato-metal-formato moieties here). The hydrogen bond between N1 and the formate atom O7 bound to uranyl [ $\mathrm{N} \cdots \mathrm{O} 3.250(3) \AA \AA, \mathrm{H} \cdots \mathrm{O} 2.56 \AA$, $\left.\mathrm{N}-\mathrm{H} \cdots \mathrm{O} 139^{\circ}\right]$, which forms a ring with the descriptor $R_{1}{ }^{1}(6)$, is typical of the mode of association of $[\mathrm{M}(\text { cyclam })]^{2+}$ and $\left[\mathrm{M}\left(R, S-\mathrm{Me} \mathrm{e}_{6} \text { cyclam }\right)\right]^{2+}$ cations with uranyl carboxylate complexes. ${ }^{[22 b, 22 c, 23]}$ It probably contributes to the incorporation of these cations in the coordination polymer through axial coordination of the transition metal ion, and thus to the increase in dimensionality through linking together uranyl-only 1D polymeric subunits. The layers in $\mathbf{5}$ are slightly corrugated and they pack so as to define narrow channels containing the acetonitrile solvent molecules, the KPI being 0.69 .

Complex 6, $\left[\mathrm{UO}_{2}(\mathrm{ADA})_{2} \mathrm{Ni}\left(R, S-\mathrm{Me}_{6} \mathrm{cyclam}\right)\right]$, was obtained in the same experimental conditions as $\mathbf{5}$, with $\mathrm{ADA}^{2-}$ in place of $\mathrm{ADC}^{2-}$. No formate anion is present here and as a result the $\mathrm{U} /$ dicarboxylate/Ni stoichiometry is different, 2:2:1 in 5, and 1:2:1 in $\mathbf{6}$. The unique $\mathrm{U}^{\mathrm{VI}}$ and $\mathrm{Ni}^{\mathrm{II}}$ centres are both located on an inversion centre. The former is in a hexagonal bipyramidal environment, but it is not tris-chelated here, being instead chelated by two carboxylate groups in trans positions and bound to two more carboxylate donors [U-O(oxo) $1.775(2) \AA$, U- 
O(carboxylato) $2.478(2)$ and $2.542(2) \AA$ for the chelating group, and $2.405(2) \AA$ for the other carboxylate donor] (Figure 6). The nickel(II) cation is bound to the four macrocyclic nitrogen
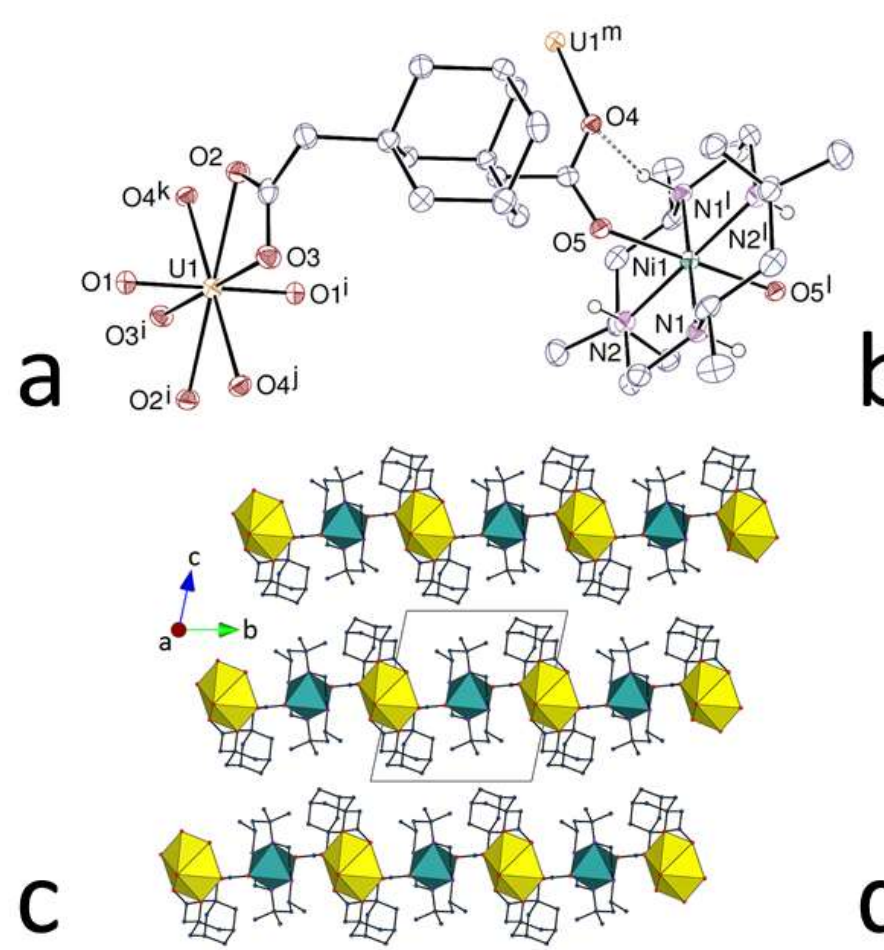
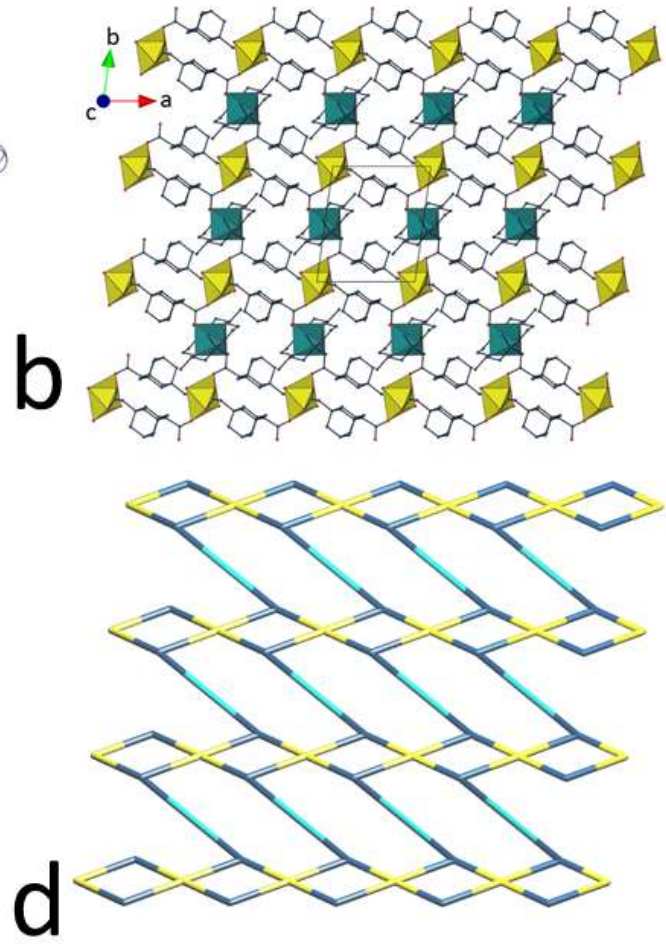

Figure 6. (a) View of complex 6. Displacement ellipsoids are drawn at the $40 \%$ probability level. Carbon-bound hydrogen atoms are omitted, and the hydrogen bond is shown as a dashed line. Symmetry codes: $\mathrm{i}=-x, 2-y, 1-z$; $\mathrm{j}=x-1, y, z ; \mathrm{k}=1-x, 2-y, 1-z ; \mathrm{I}=2-x, 1-y, 1-z ; \mathrm{m}=x+1, y, z$. (b) View of the 2D network with uranium coordination polyhedra colored yellow and those of nickel(II) green. (c) Packing with layers viewed edge-on. (d) Nodal representation of the network (yellow: uranium nodes, dark blue: ADA ${ }^{2-}$ nodes, light blue: nickel(II) links), same orientation as in (b).

atoms and two axial carboxylate donors [Ni-N 2.072(3) and 2.098(3) $\AA, \mathrm{Ni}-\mathrm{O} 2.165(2) \AA]$, with

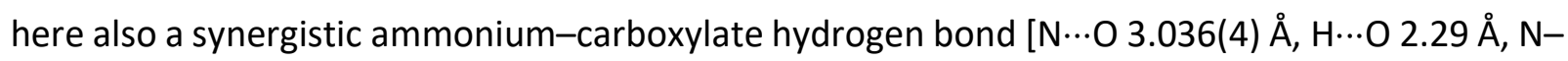
$\mathrm{H} \cdots \mathrm{O} 137^{\circ}$ ] defining a $R_{1}^{1}(6)$ ring. As in 5 , uranium is a fourfold node and the $A D A^{2-}$ ligand, bound in $\kappa^{2} O, O^{\prime} / \mu_{2}-\kappa^{1} O: \kappa^{1} O^{\prime}$ mode, a threefold one, and nickel(II) cations are simple links. The $2 \mathrm{D}$ 
assembly formed is parallel to (001) and it has the point symbol $\left\{4.6^{2}\right\}_{2}\left\{4^{2} \cdot 6^{2} .8^{2}\right\}$ and the topological type $\mathbf{3 , 4 L 1 3}$, previously found in homometallic uranyl ion complexes with $4,4^{\prime}$ biphenyldicarboxylate, with permutation of the metal and ligand roles. ${ }^{[24]}$ As in complex 5, 1D uranyl-containing chains are assembled into a 2D network by the bridging $\mathrm{Ni}^{\mathrm{Il}}$ cations, and the packing does not contain significant free spaces (KPI 0.67).

The last complex in this series, $\left[\mathrm{UO}_{2}(\mathrm{ADA})(\mathrm{DMPU})\right](7)$, is homometallic and neutral. It is very close to the complex $\left[\mathrm{UO}_{2}(\mathrm{ADA})(\mathrm{DMF})\right]$ previously reported, ${ }^{[5]}$ and will thus only be briefly described in consequence. The unique uranium atom is chelated by one carboxylate group and bound to two more carboxylate and one DMPU oxygen atoms [U-O(oxo) $1.769(2)$ and $1.770(2)$ $\AA$, U-O(carboxylato) $2.428(2)$ and $2.464(2) \AA$ for the chelating group, $2.311(2)$ and $2.370(2) \AA$ for the other carboxylate donors, and 2.3508(18) ̊̊ for DMPU] (Figure 7). The 2D assembly formed is parallel to (101) and it has the point symbol $\left\{4.8^{2}\right\}$ and the common fes topological type. With a $\mathrm{KPI}$ of 0.68 , the packing is compact and does not contain solvent-accessible free spaces. It is notable that, although they display the same coordination mode of the ligand, the complexes $\left[\mathrm{UO}_{2}(\mathrm{ADA})\left(\mathrm{H}_{2} \mathrm{O}\right)\right]$ and $\left[\mathrm{UO}_{2}(\mathrm{ADA})(\mathrm{NMP})\right](\mathrm{NMP}=\mathrm{N}$-methyl-2-pyrrolidone) crystallize as $1 \mathrm{D}$ coordination polymers, ${ }^{[5]}$ due to a different orientation of the acetate arms. With also an identical coordination mode but shorter substituents, the complexes $\left[\mathrm{UO}_{2}(\mathrm{ADC})\left(\mathrm{H}_{2} \mathrm{O}\right)\right]$ (different solvates) and $\left[\mathrm{UO}_{2}(\mathrm{ADC})(\mathrm{DMF})\right]$ crystallize also as simple $1 \mathrm{D}$ chains, ${ }^{[3,4]}$ while a more intricate $1 \mathrm{D}$ arrangement is found in $\left[\mathrm{UO}_{2}(\mathrm{ADC})(\mathrm{NMP})\right]^{[4]}$ 

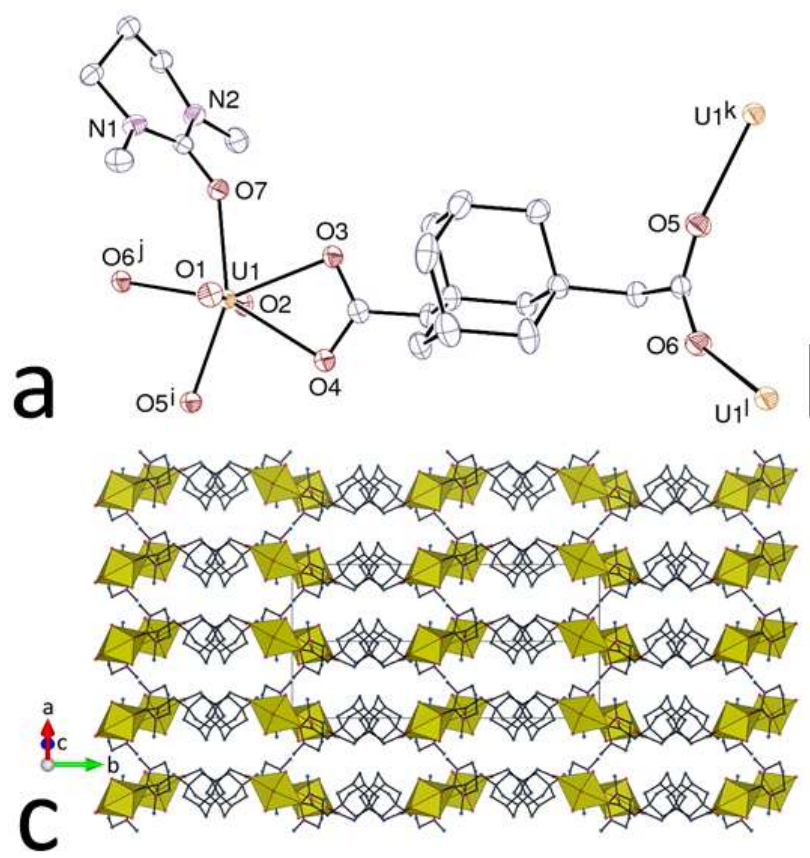
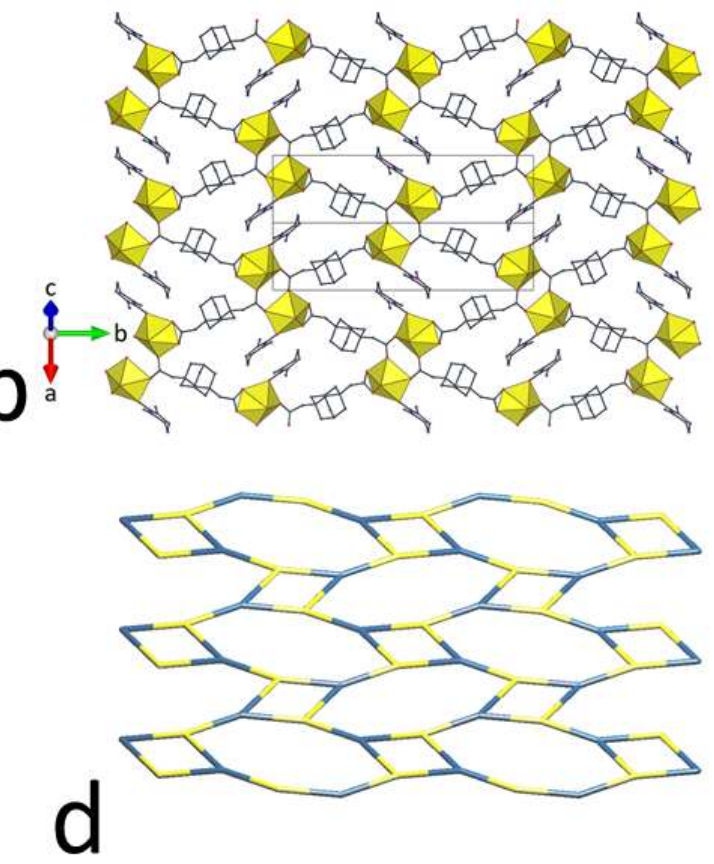

Figure 7. (a) View of complex 7. Displacement ellipsoids are drawn at the $50 \%$ probability level. Symmetry codes: $\mathrm{i}=$ $x-1 / 2,1 / 2-y, z+1 / 2 ; j=3 / 2-x, y+1 / 2,1 / 2-z ; k=x+1 / 2,1 / 2-y, z-1 / 2 ; l=3 / 2-x, y-1 / 2,1 / 2-z$. (b) View of the 2D network with uranium coordination polyhedra colored yellow. (c) Packing with layers viewed edge-on. Hydrogen atoms are omitted in all views. (d) Nodal representation of the 2D network (uranium nodes, yellow; dicarboxylate nodes, blue), same orientation as in (b).

\section{Luminescence Properties}

The emission spectra of complexes 1-7 in the solid state were recorded at room temperature under excitation at a wavelength of $420 \mathrm{~nm}$, a value suitable for excitation of the uranyl chromophore, ${ }^{[25]}$ and they are shown in Figure 8. With the exception of complex 6 which is nonluminescent, probably as a result of quenching due to $\mathrm{Ni}^{\prime l}$ providing a nonradiative relaxation pathway $^{[26]}$ (a lesser effect being also partially present in compound 5), all complexes give spectra displaying well-resolved emission peaks typical of the vibronic progression corresponding to the $S_{11} \rightarrow S_{00}$ and $S_{10} \rightarrow S_{0 v}(v=0-4)$ electronic transitions. ${ }^{[27]}$ The three complexes $\mathbf{2}, \mathbf{3}$ and $\mathbf{4}$, in 


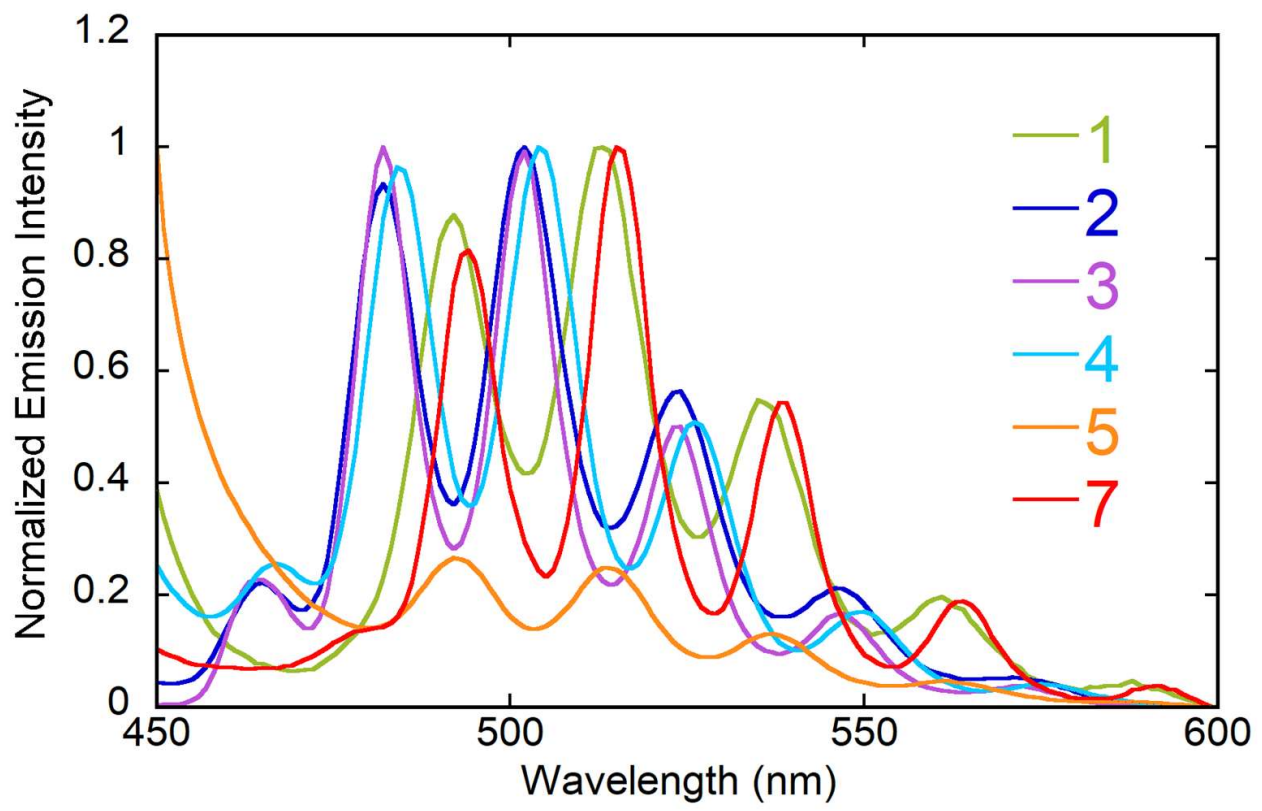

Figure 8. Solid state uranyl emission spectra of complexes 1-5 and $\mathbf{7}$ measured with an excitation wavelength of 420 $\mathrm{nm}$. Complex 6 is non-luminescent.

which the uranyl cation has six equatorial oxygen donors, display the most blueshifted emission peaks, with the main maxima at 482, 502, 524 and $546 \mathrm{~nm}$ for 2 and 3, the values for 4 being redshifted by about $2 \mathrm{~nm}$. These values are typical of uranyl tris-chelated carboxylate complexes. ${ }^{[28]}$ The two complexes with five equatorial oxygen donors, $\mathbf{5}$ and $\mathbf{7}$, give maxima redshifted by about 10-18 $\mathrm{nm}$ with respect to the previous ones, at 492/494, 514/515, 537/539 and $562 / 564 \mathrm{~nm}$, also in agreement with former observations, ${ }^{[28]}$ and probably a consequence of an increase in donor strength of the equatorial ligands inducing a decrease in uranyl oxo bond order. $^{[29]}$ The case of complex 1 is however peculiar, since, although the uranyl cation has six equatorial oxygen donors, the positions of the maxima, at 492, 513, 535 and $561 \mathrm{~nm}$, are close to those for complexes $\mathbf{5}$ and $\mathbf{7}$. This redshift is possibly to be ascribed to replacement of one of the three chelating carboxylate groups present in $\mathbf{2 - 4}$ by a chelating nitrate in $\mathbf{1}$, and it may be noted 
that the maxima for uranyl nitrate hexahydrate (with two chelating nitrates and two water molecules in the equatorial plane) are at $486,508,532$ and $557 \mathrm{~nm}$, i.e. redshifted by about 4-9 $\mathrm{nm}$ with respect to the positions measured for tris-chelated carboxylate complexes (but still less than the values for 1). However, such an effect was not observed previously in other uranyl carboxylate complexes in which a nitrate anion was retained as a coligand, ${ }^{[22 b, 30]}$ so that its origin here remains obscure. The solid-state photoluminescence quantum yields (PLQYs) are low $(\leq 1 \%)$ for all compounds but 3 , for which the moderate value of $5 \%$ has been measured. Such values are usual for uranyl carboxylate complexes, ${ }^{[16,22 b, 31]}$ although in some cases much larger yields were found, ${ }^{[30 d, 32]}$ comparable to or larger than that of $24 \%$ for uranyl nitrate hexahydrate.

\section{Conclusions}

We have reported the synthesis, crystal structure and solid-state emission spectrum of seven homo- or heterometallic uranyl complexes with the ligands $\mathrm{ADC}^{2-}$ or $\mathrm{ADA}^{2-}$. The complexes obtained with phosphonium counterions, $\mathrm{PPh}_{4}{ }^{+}$and $\mathrm{PPh}_{3} \mathrm{Me}^{+}$, are anionic and crystallize as monoperiodic coordination polymers, as does the complex with separate $\left[\mathrm{Ni}(\mathrm{cyclen})\left(\mathrm{H}_{2} \mathrm{O}\right)\right]^{2+}$ counterions. In most cases, these chains have a trough-like shape and some of them are paired so as to define a central space containing the counterions. A notable feature of these structures is that they reveal similar binding characteristics of the ligands $A D C^{2-}$ and $A D A^{2-}$ in these complexes where the uranyl/carboxylate ratio is 2:3. Bridging of 1D uranyl-containing subunits through axial coordination of $\left[\mathrm{Ni}\left(R, S-\mathrm{Me}_{6} \mathrm{Cyclam}\right)\right]^{2+}$ counterions gives diperiodic networks with both $\mathrm{ADC}^{2-}$ or $\mathrm{ADA}^{2-}$ ligands. A neutral, homometallic diperiodic network is also obtained with $\mathrm{ADA}^{2-}$ when $N, N^{\prime}$-dimethylpropyleneurea (DMPU) is present as a coligand. Overall, in these and 
previous experiments with these ligands, neither $\mathrm{ADC}^{2-}$ nor $\mathrm{ADA}^{2-}$ displays a rich diversity of coordination modes toward the uranyl ion, since in the vast majority of cases only two modes are found, either bis- $\kappa^{2} O, O^{\prime}$ (bis-chelating) or $\kappa^{2} O, O^{\prime} / \mu_{2}-\kappa^{1} O: \kappa^{1} O^{\prime}$ (chelating and bridging). Only in two complexes with $\mathrm{ADC}^{2-}$ were additional modes observed, bis- $\mu_{2}-\kappa^{2} O, O^{\prime}: \kappa^{1} O^{\prime}$ (bis-chelatingbridging), and bis- $\mu_{2}-\kappa^{1} O: \kappa^{1} O^{\prime}$ (bis-bridging). ${ }^{[4]}$ Varying the experimental conditions of the syntheses, in particular the nature of the counterions, allows however some structural variety in the complexes formed. This is particularly true for the more flexible ADA ${ }^{2-}$ ligand, since in $A D C^{2-}$, the $\mathrm{C}-\mathrm{CO}_{2}-$ bonds must have a convergent orientation, even if not one that would enable binding of both groups to a single $U^{\mathrm{VI}}$ centre, whereas the greater rotational freedom of $\mathrm{ADA}^{2-}$ enables orientations of the carboxylate groups much closer to divergent. This does lead to differences between the trough-like polymers but these are not such as to alter its basic form, which has a profile indicating convergence to a closed oligomer form should be possible. While this has not been attained with $\mathrm{ADC}^{2-}$, it has been found in the tetranuclear metallatricycle with $\mathrm{ADA}^{2-}$ previously reported. ${ }^{[7]}$ This closed species is associated with both $\mathrm{NH}_{4}{ }^{+}$and phosphonium $\left(\mathrm{PPh}_{4}{ }^{+}\right.$ or $\mathrm{PPh}_{3} \mathrm{Me}^{+}$) cations. While an earlier result had shown that replacement of $\mathrm{NH}_{4}{ }^{+}$by $\mathrm{H}_{2} \mathrm{NMe}_{2}{ }^{+}$ prevented formation of the closed species and gave instead a diperiodic network, ${ }^{[7]}$ the monoperiodic nature of complex 3 demonstrates the inability of $\mathrm{PPh}_{4}{ }^{+}$cations alone to promote the formation of the discrete tetranuclear species. Both $\mathrm{NH}_{4}{ }^{+}$and phosphonium cations thus appear to be necessary to the formation of the latter, most probably as a result of their close association with it through weak interactions (particularly multiple $\mathrm{NH} \cdots \mathrm{O}$ hydrogen bonding in the case of ammonium). While this work has shown that the nature of the anionic uranyl ion coordination polymers formed is strongly dependent on the nature of the counterion, there is an 
interesting possibility that ion exchange reactions of the crystalline solids might result in retention of the anion structure with selective binding to another cation ${ }^{[33]}$ and such a process may merit investigation, though probably by non-solvothermal methods.

Except for one heterometallic complex which is non-luminescent, all the present compounds give solid-state emission spectra displaying the usual uranyl emission vibronic fine structure, with maxima positions in keeping with the number of equatorial donors, except in the case of the complex retaining a chelating nitrate. The solid-state photoluminescence quantum yields are low, an obvious drawback for any application of such uranyl complexes as photocatalysts.

\section{Experimental Section}

General: $\mathrm{UO}_{2}\left(\mathrm{NO}_{3}\right)_{2} \cdot 6 \mathrm{H}_{2} \mathrm{O}$ (depleted uranium, R. P. Normapur, 99\%) was purchased from Prolabo. 1,3-Adamantanedicarboxylic acid $\left(\mathrm{H}_{2} \mathrm{ADC}\right)$ and 1,3-adamantanediacetic acid $\left(\mathrm{H}_{2} \mathrm{ADA}\right)$ were from Aldrich. [ $\left.\mathrm{Ni}\left(\mathrm{R}, \mathrm{S}-\mathrm{Me}_{6} \mathrm{Cyclam}\right)\left(\mathrm{NO}_{3}\right)_{2}\right]$ was synthesized as previously described. ${ }^{[23]}$ Elemental analyses for compounds $\mathbf{1 - 5}$ and $\mathbf{7}$ were performed by MEDAC Ltd. at Chobham, UK. A similar analysis could not be conducted for compound $\mathbf{6}$ due to the low yield of the synthesis. For all syntheses, the mixtures in demineralized water were placed in $10 \mathrm{~mL}$ tightly closed glass vessels and heated at $140{ }^{\circ} \mathrm{C}$ under autogenous pressure.

Caution! Uranium is a radioactive and chemically toxic element, and uranium-containing samples must be handled with suitable care and protection.

[Ni(cyclen)( $\left.\mathrm{NO}_{3}\right)_{2}$ ]: Separate solutions of cyclen $(\mathrm{O} .17 \mathrm{~g}, 1.00 \mathrm{mmol})$ in $\mathrm{CH}_{3} \mathrm{OH}(5 \mathrm{~mL})$ and [Ni( $\left.\left(\mathrm{H}_{2} \mathrm{O}\right)_{6}\right]\left(\mathrm{NO}_{3}\right)_{2}(0.29 \mathrm{~g}, 1.00 \mathrm{mmol})$ in $\mathrm{CH}_{3} \mathrm{OH}(5 \mathrm{~mL})$ were mixed to immediately provide a deep 
violet solution. Diethylether $(10 \mathrm{~mL})$ was added to provide violet crystals of [Ni(cyclen $\left.)\left(\mathrm{NO}_{3}\right)_{2}\right]$, and another $10 \mathrm{~mL}$ was added after 5 min to give essentially complete precipitation.

[PPh 3 Me][UO $\left.{ }_{2}(\mathrm{ADC})\left(\mathrm{NO}_{3}\right)\right]$ (1): $\mathrm{H}_{2} \mathrm{ADC}(22 \mathrm{mg}, 0.10 \mathrm{mmol}), \mathrm{UO}_{2}\left(\mathrm{NO}_{3}\right)_{2} \cdot 6 \mathrm{H}_{2} \mathrm{O}(35 \mathrm{mg}, 0.07 \mathrm{mmol})$, and $\mathrm{PPh}_{3} \mathrm{MeBr}(36 \mathrm{mg}, 0.10 \mathrm{mmol})$ were dissolved in a mixture of water $(0.6 \mathrm{~mL})$, acetonitrile $(0.2$ $\mathrm{mL}$ ), and THF ( $0.2 \mathrm{~mL}$ ). Yellow crystals of complex 1 were obtained within three days ( $26 \mathrm{mg}, 45 \%$ yield based on U). $\mathrm{C}_{31} \mathrm{H}_{32} \mathrm{NO}_{9} \mathrm{PU}$ (831.57): calcd. C 44.78, $\mathrm{H} 3.88, \mathrm{~N} 1.68$; found $\mathrm{C} 44.95, \mathrm{H} 3.80, \mathrm{~N}$ 1.68 .

$\left[\mathrm{PPh}_{4}\right]_{2}\left[\left(\mathrm{UO}_{2}\right)_{2}(\mathrm{ADC})_{3}\right] \cdot 2 \mathrm{H}_{2} \mathrm{O}(2): \mathrm{H}_{2} \mathrm{ADC}(22 \mathrm{mg}, 0.10 \mathrm{mmol}), \mathrm{UO}_{2}\left(\mathrm{NO}_{3}\right)_{2} \cdot 6 \mathrm{H}_{2} \mathrm{O}(35 \mathrm{mg}, 0.07 \mathrm{mmol})$, and $\mathrm{PPh}_{4} \mathrm{Br}$ (42 $\left.\mathrm{mg}, 0.10 \mathrm{mmol}\right)$ were dissolved in a mixture of water $(0.6 \mathrm{~mL}), \mathrm{DMF}(0.2 \mathrm{~mL})$, and THF $(0.2 \mathrm{~mL})$. Yellow crystals of complex 2 were obtained within one week ( $38 \mathrm{mg}, 57 \%$ yield). Elemental analysis results indicate the probable presence of about four extra water molecules, in excess of those found from structure determination. $\mathrm{C}_{84} \mathrm{H}_{86} \mathrm{O}_{18} \mathrm{P}_{2} \mathrm{U}_{2}+4 \mathrm{H}_{2} \mathrm{O}$ (1993.58): calcd. $\mathrm{C}$ 50.61, H 4.75; found C 50.48, H 4.51.

$\left[\mathrm{PPh}_{4}\right]_{2}\left[\left(\mathrm{UO}_{2}\right)_{2}(\mathrm{ADA})_{3}\right](3): \mathrm{H}_{2} \mathrm{ADA}(25 \mathrm{mg}, 0.10 \mathrm{mmol}), \mathrm{UO}_{2}\left(\mathrm{NO}_{3}\right)_{2} \cdot 6 \mathrm{H}_{2} \mathrm{O}(35 \mathrm{mg}, 0.07 \mathrm{mmol})$, and $\mathrm{PPh}_{4} \mathrm{Br}(42 \mathrm{mg}, 0.10 \mathrm{mmol})$ were dissolved in a mixture of water $(0.5 \mathrm{~mL})$ and $\mathrm{DMF}(0.2 \mathrm{~mL})$. Yellow crystals of complex 3 were obtained within two weeks (29 mg, $42 \%$ yield). $\mathrm{C}_{90} \mathrm{H}_{94} \mathrm{O}_{16} \mathrm{P}_{2} \mathrm{U}_{2}$ (1969.65): calcd. C 54.88, H 4.81; found C 54.00, H 4.69.

[Ni(cyclen)( $\left.\left.\mathrm{H}_{2} \mathrm{O}\right)\right]\left[\left(\mathrm{UO}_{2}\right)_{2}(\mathrm{ADC})_{3}\right] \cdot \mathrm{H}_{2} \mathrm{O}(4): \mathrm{H}_{2} \mathrm{ADC}(22 \mathrm{mg}, 0.10 \mathrm{mmol}), \mathrm{UO}_{2}\left(\mathrm{NO}_{3}\right)_{2} \cdot 6 \mathrm{H}_{2} \mathrm{O}(35 \mathrm{mg}$, $0.07 \mathrm{mmol})$, and $\left[\mathrm{Ni}(\mathrm{cyclen})\left(\mathrm{NO}_{3}\right)_{2}\right](18 \mathrm{mg}, 0.05 \mathrm{mmol})$ were dissolved in a mixture of water $(0.6$ $\mathrm{mL})$, DMF $(0.2 \mathrm{~mL})$, and acetonitrile $(0.2 \mathrm{~mL})$. Yellow-green crystals of complex 4 were obtained within four days (20 mg, 39\% yield based on U). $\mathrm{C}_{44} \mathrm{H}_{66} \mathrm{~N}_{4} \mathrm{NiO}_{18} \mathrm{U}_{2}$ (1473.77): calcd. C 35.86, H 4.51, N 3.80; found C 34.95, H 4.48, N 4.20. 
$\left[\left(\mathrm{UO}_{2}\right)_{2}(\mathrm{ADC})_{2} \mathrm{Ni}\left(\mathrm{R}, \mathrm{S}-\mathrm{Me}_{6} \mathrm{Cyclam}\right)(\mathrm{HCOO})_{2}\right] \cdot \mathrm{CH}_{3} \mathrm{CN} \quad(5): \mathrm{H}_{2} \mathrm{ADC} \quad(22 \mathrm{mg}, \quad 0.10 \mathrm{mmol})$, $\mathrm{UO}_{2}\left(\mathrm{NO}_{3}\right)_{2} \cdot 6 \mathrm{H}_{2} \mathrm{O}(35 \mathrm{mg}, 0.07 \mathrm{mmol})$, and $\left[\mathrm{Ni}\left(R, S-\mathrm{Me}_{6} \mathrm{Cyclam}\right)\left(\mathrm{NO}_{3}\right)_{2}\right](23 \mathrm{mg}, 0.05 \mathrm{mmol})$ were dissolved in a mixture of water $(0.7 \mathrm{~mL}), \mathrm{DMF}(0.2 \mathrm{~mL})$, and acetonitrile $(0.2 \mathrm{~mL})$. Yellow-green crystals of complex 5 were obtained within four days (32 mg, 63\% yield based on $U$ ). $\mathrm{C}_{44} \mathrm{H}_{69} \mathrm{~N}_{5} \mathrm{NiO}_{16} \mathrm{U}_{2}$ (1458.81): calcd. C 36.23, H 4.77, N 4.80; found C 35.91, H 4.51, N 4.56.

[UO $\left.{ }_{2}(\mathrm{ADA})_{2} \mathrm{Ni}\left(\mathrm{R}, \mathrm{S}-\mathrm{Me}_{6} \mathrm{cyclam}\right)\right]$ (6): $\mathrm{H}_{2} \mathrm{ADA}(25 \mathrm{mg}, 0.10 \mathrm{mmol}), \mathrm{UO}_{2}\left(\mathrm{NO}_{3}\right)_{2} \cdot 6 \mathrm{H}_{2} \mathrm{O}(35 \mathrm{mg}, 0.07$ $\mathrm{mmol})$, and $\left[\mathrm{Ni}\left(R, S-\mathrm{Me}_{6} \mathrm{Cyclam}\right)\left(\mathrm{NO}_{3}\right)_{2}\right](23 \mathrm{mg}, 0.05 \mathrm{mmol})$ were dissolved in a mixture of water $(0.5 \mathrm{~mL}), \operatorname{DMF}(0.2 \mathrm{~mL})$, and acetonitrile $(0.2 \mathrm{~mL})$. Orange-pink crystals of complex 6 were obtained in low yield within one week. The yield was not improved upon prolonged heating.

[UO $\left.{ }_{2}(A D A)(D M P U)\right](7): \mathrm{H}_{2} A D A(25 \mathrm{mg}, 0.10 \mathrm{mmol})$ and $\mathrm{UO}_{2}\left(\mathrm{NO}_{3}\right)_{2} \cdot 6 \mathrm{H}_{2} \mathrm{O}(50 \mathrm{mg}, 0.10 \mathrm{mmol})$ were dissolved in a mixture of water $(0.9 \mathrm{~mL})$ and DMPU $(0.2 \mathrm{~mL})$. Yellow crystals of complex 7 were obtained within one week ( $30 \mathrm{mg}, 46 \%$ yield based on the acid). $\mathrm{C}_{20} \mathrm{H}_{30} \mathrm{~N}_{2} \mathrm{O}_{7} \mathrm{U}$ (648.49): calcd. $\mathrm{C}$ 37.04, H 4.66, N 4.32; found C 37.23, H 4.79, N 4.18.

Crystallography: The data were collected at 100(2) K on a Nonius Kappa-CCD area detector diffractometer ${ }^{[34]}$ using graphite-monochromated Mo K $\alpha$ radiation $(\lambda=0.71073 \AA)$. The crystals were introduced into glass capillaries with a protective coating of Paratone- $\mathrm{N}$ oil (Hampton Research). The unit cell parameters were determined from ten frames, then refined on all data. The data (combinations of $\varphi$ - and $\omega$-scans with a minimum redundancy of at least 4 for $90 \%$ of the reflections) were processed with HKL2000. ${ }^{[35]}$ Absorption effects were corrected for empirically with the program SCALEPACK. ${ }^{[35]}$ The structures were solved by intrinsic phasing with SHELXT, ${ }^{[36]}$ expanded by subsequent difference Fourier synthesis and refined by full-matrix least- 
squares on $F^{2}$ with SHELX[ ${ }^{[37]}$ using the SHELXle graphical user interface. ${ }^{[38]}$ All non-hydrogen atoms were refined with anisotropic displacement parameters. When present, the hydrogen atoms bound to oxygen or nitrogen atoms were found on difference Fourier maps, except in cases indicated below, and the carbon-bound hydrogen atoms were introduced at calculated positions. All hydrogen atoms were treated as riding atoms with an isotropic displacement parameter equal to 1.2 times that of the parent atom ( 1.5 for $\mathrm{CH}_{3}$, with optimized geometry). Crystal data and structure refinement parameters are given in Table 1 . The molecular plots were drawn with ORTEP-3 ${ }^{[39]}$ and the polyhedral representations with VESTA. ${ }^{[0]}$ Topological analyses were conducted with ToposPro. ${ }^{[41]}$ Special details are as follows:

Compound 3. Some voids in the structure indicate the presence of water solvent molecules which appear to be highly disordered and could not be modelled properly. Their contribution to the structure factors was taken into account with PLATON/SQUEEZE. ${ }^{[42]}$

Compound 4. The $\left[\mathrm{Ni}(\text { cyclen })\left(\mathrm{H}_{2} \mathrm{O}\right)\right]^{2+}$ moiety is highly disordered over a plane of symmetry. One complete molecule was refined with restraints on bond lengths, angles and displacement parameters, but this part of the structure can only be considered approximate. The hydrogen atoms bound to nitrogen atoms were introduced at calculated positions, and those of the water molecules were neither found, nor introduced.

CCDC-1950509-1950515 contain the supplementary crystallographic data for this paper. These data can be obtained free of charge from The Cambridge Crystallographic Data Centre via www.ccdc.cam.ac.uk/data request/cif. 
Table 1. Crystal data and structure refinement details.

\begin{tabular}{|c|c|c|c|c|c|c|c|}
\hline & 1 & 2 & 3 & 4 & 5 & 6 & 7 \\
\hline Empirical formula & $\mathrm{C}_{31} \mathrm{H}_{32} \mathrm{NO}_{9} \mathrm{PU}$ & $\mathrm{C}_{84} \mathrm{H}_{86} \mathrm{O}_{18} \mathrm{P}_{2} \mathrm{U}_{2}$ & $\mathrm{C}_{90} \mathrm{H}_{94} \mathrm{O}_{16} \mathrm{P}_{2} \mathrm{U}_{2}$ & $\mathrm{C}_{44} \mathrm{H}_{66} \mathrm{~N}_{4} \mathrm{NiO}_{18} \mathrm{U}_{2}$ & $\mathrm{C}_{44} \mathrm{H}_{69} \mathrm{~N}_{5} \mathrm{NiO}_{16} \mathrm{U}_{2}$ & $\mathrm{C}_{44} \mathrm{H}_{72} \mathrm{~N}_{4} \mathrm{NiO}_{10} \mathrm{U}$ & $\mathrm{C}_{20} \mathrm{H}_{30} \mathrm{~N}_{2} \mathrm{O}_{7} \mathrm{U}$ \\
\hline$M\left(\mathrm{~g} \mathrm{~mol}^{-1}\right)$ & 831.57 & 1921.52 & 1969.65 & 1473.77 & 1458.81 & 1113.79 & 648.49 \\
\hline Crystal system & monoclinic & monoclinic & triclinic & monoclinic & monoclinic & triclinic & monoclinic \\
\hline Space group & $P 2_{1} / n$ & $P 2_{1}$ & $P_{\mathrm{I}}^{\top}$ & $\mathrm{C} 2 / \mathrm{m}$ & $C 2 / c$ & $P_{\mathrm{I}}^{\overline{\mathrm{I}}}$ & $P 2_{1} / n$ \\
\hline$a(\AA)$ & $13.3352(6)$ & $10.0202(3)$ & $9.9762(3)$ & $36.526(2)$ & $15.7165(4)$ & $9.1743(5)$ & $7.6018(3)$ \\
\hline$b(\AA)$ & $15.0239(7)$ & $18.0979(9)$ & $19.7489(10)$ & $9.9335(3)$ & $14.8628(7)$ & $11.0514(9)$ & $24.9860(12)$ \\
\hline$c(\AA)$ & $15.5226(4)$ & $21.7247(10)$ & $21.4665(10)$ & $16.4695(12)$ & 21.8829(9) & $11.9129(10)$ & $11.5677(5)$ \\
\hline$\alpha\left(^{\circ}\right)$ & 90 & 90 & $104.360(2)$ & 90 & 90 & $76.756(4)$ & 90 \\
\hline$\beta\left({ }^{\circ}\right)$ & $97.873(3)$ & $97.154(3)$ & $91.041(3)$ & $114.889(3)$ & $100.156(3)$ & $80.817(3)$ & $92.039(3)$ \\
\hline$\gamma\left({ }^{\circ}\right)$ & 90 & 90 & $98.130(3)$ & 90 & 90 & $80.338(4)$ & 90 \\
\hline$V\left(\AA^{3}\right)$ & $3080.6(2)$ & $3909.0(3)$ & $4049.7(3)$ & $5420.7(5)$ & $5031.6(3)$ & $1149.76(15)$ & $2195.76(17)$ \\
\hline$z$ & 4 & 2 & 2 & 4 & 4 & 1 & 4 \\
\hline Reflections collected & 100004 & 125033 & 221303 & 94026 & 88673 & 54544 & 115541 \\
\hline Independent reflections & 5850 & 14818 & 15373 & 5450 & 4760 & 4358 & 6691 \\
\hline Observed reflections $[I>2 \sigma(I)]$ & 4142 & 13556 & 12731 & 4428 & 4430 & 4159 & 5341 \\
\hline$R_{\text {int }}$ & 0.036 & 0.032 & 0.059 & 0.041 & 0.024 & 0.061 & 0.049 \\
\hline$w R_{2}$ & 0.078 & 0.084 & 0.064 & 0.118 & 0.047 & 0.062 & 0.067 \\
\hline$S$ & 1.035 & 1.088 & 1.034 & 1.045 & 1.063 & 1.008 & 0.983 \\
\hline$\Delta \rho_{\min }\left(\mathrm{e} \AA^{-3}\right)$ & -1.36 & -0.97 & -0.98 & -2.43 & -1.12 & -1.16 & -1.57 \\
\hline$\Delta \rho_{\max }\left(\mathrm{e} \AA^{-3}\right)$ & 0.98 & 1.30 & 0.84 & 2.29 & 1.05 & 0.63 & 2.13 \\
\hline Flack parameter & & $-0.008(6)$ & & & & & \\
\hline
\end{tabular}

Luminescence measurements: Emission spectra were recorded on solid samples using a HoribaJobin-Yvon IBH FL-322 Fluorolog 3 spectrometer equipped with a $450 \mathrm{~W}$ xenon arc lamp, doublegrating excitation and emission monochromators $(2.1 \mathrm{~nm} / \mathrm{mm}$ of dispersion; 1200 grooves $/ \mathrm{mm})$ and a TBX-04 single photon-counting detector. The powdered compounds were pressed to the wall of a quartz tube, and the measurements were performed using the right-angle mode. An excitation wavelength of $420 \mathrm{~nm}$, a commonly used point although only part of a broad manifold, was used in all cases and the emission was monitored between 450 and $650 \mathrm{~nm}$. The quantum yield measurements were performed by using a Hamamatsu Quantaurus C11347 absolute photoluminescence quantum yield spectrometer and exciting the samples between 300 and 400 $\mathrm{nm}$. 


\section{References}

[1] a) C. R. Groom, I. J. Bruno, M. P. Lightfoot, S. C. Ward, Acta Crystallogr., Sect. B 2016, 72, 171-179; b) R. Taylor, P. A. Wood, Chem. Rev. 2019, 119, 9427-9477.

[2] a) M. B. Andrews, C. L. Cahill, Chem. Rev. 2013, 113, 1121-1136; b) T. Loiseau, I. Mihalcea, N. Henry, C. Volkringer, Coord. Chem. Rev. 2014, 266-267, 69-109; c) J. Su, J. S. Chen, Struct. Bond. 2015, 163, 265-296; d) P. Thuéry, J. Harrowfield, Dalton Trans. 2017, 46, $13660-13667$.

[3] J. A. Rusanova, E. B. Rusanov, K. V. Domasevitch, Acta Crystallogr., Sect. C 2010, 66, m207$\mathrm{m} 210$.

[4] P. Thuéry, E. Rivière, J. Harrowfield, Inorg. Chem. 2015, 54, 2838-2850.

[5] P. Thuéry, J. Harrowfield, CrystEngComm 2015, 17, 4006-4018.

[6] P. Thuéry, Eur. J. Inorg. Chem. 2017, 2876-2882.

[7] P. Thuéry, Y. Atoini, J. Harrowfield, Inorg. Chem. 2018, 57, 7932-7939.

[8] a) K. M. Ok, D. O'Hare, Dalton Trans. 2008, 5560-5562; b) O. M. Nazarenko, J. A. Rusanova, H. Krautscheid, K. V. Domasevitch, Acta Crystallogr., Sect. C 2010, 66, m276-m279.

[9] a) I. Dance, M. Scudder, Chem. Eur. J. 1996, 2, 481-486; b) M. Scudder, I. Dance, J. Chem. Soc., Dalton Trans. 1998, 3155-3165.

[10] a) R. Taylor, O. Kennard, J. Am. Chem. Soc. 1982, 104, 5063-5070; b) G. R. Desiraju, Acc. Chem. Res. 1996, 29, 441-449.

[11] M. A. Spackman, D. Jayatilaka, CrystEngComm 2009, 11, 19-32, and references therein.

[12] S. K. Wolff, D. J. Grimwood, J. J. McKinnon, M. J. Turner, D. Jayatilaka, M. A. Spackman, CrystalExplorer, University of Western Australia, 2012. 
[13] A. L. Spek, Acta Crystallogr., Sect. D 2009, 65, 148-155.

[14] a) M. C. Etter, J. C. MacDonald, J. Bernstein, Acta Crystallogr., Sect. B 1990, 46, 256-262;

b) J. Bernstein, R. E. Davis, L. Shimoni, N. L. Chang, Angew. Chem. Int. Ed. 1995, 34, 15551573.

[15] P. Thuéry, J. Harrowfield, Cryst. Growth Des. 2017, 17, 2881-2892.

[16] P. Thuéry, Y. Atoini, J. Harrowfield, Inorg. Chem. 2018, 57, 6283-6288.

[17] P. Thuéry, J. Harrowfield, Cryst. Growth Des. 2017, 17, 963-966.

[18] S. Pasquale, S. Sattin, E. C. Escudero-Adán, M. Martínez-Belmonte, J. de Mendoza, Nature Commun. 2012, 3, 785-791.

[19] J. H. Coates, D. A. Hadi, S. F. Lincoln, H. W. Dodgen, J. P. Hunt, Inorg. Chem. 1981, 20, 707711.

[20] J. Li, Y. W. Ren, J. H. Zhang, P. Yang, J. Chem. Cryst. 2004, 34, 409-413.

[21] B. Bosnich, C. K. Poon, M. L. Tobe, Inorg. Chem. 1965, 4, 1102-1108.

[22] a) P. Thuéry, J. Harrowfield, Cryst. Growth Des. 2016, 16, 7083-7093; b) P. Thuéry, Y. Atoini, J. Harrowfield, Inorg. Chem. 2019, 58, 567-580; c) P. Thuéry, Y. Atoini, J. Harrowfield, Cryst. Growth Des. 2019, 19, 4109-4120.

[23] P. Thuéry, J. Harrowfield, Cryst. Growth Des. 2018, 18, 5512-5520.

[24] P. Thuéry, J. Harrowfield, Inorg. Chem. 2015, 54, 8093-8102.

[25] K. E. Knope, D. T. de Lill, C. E. Rowland, P. M. Cantos, A. de Bettencourt-Dias, C. L. Cahill, Inorg. Chem. 2012, 51, 201-206.

[26] A. T. Kerr, C. L. Cahill, Cryst. Growth Des. 2014, 14, 1914-1921.

[27] A. Brachmann, G. Geipel, G. Bernhard, H. Nitsche, Radiochim. Acta 2002, 90, 147-153. 
[28] P. Thuéry, J. Harrowfield, Inorg. Chem. 2017, 56, 13464-13481.

[29] a) M. P. Redmond, S. M. Cornet, S. D. Woodall, D. Whittaker, D. Collison, M. Helliwell, L. S. Natrajan, Dalton Trans. 2011, 40, 3914-3926; b) L. S. Natrajan, Coord. Chem. Rev. 2012, 256, 1583-1603.

[30] a) P. Thuéry, E. Rivière, J. Harrowfield, Cryst. Growth Des. 2016, 16, 2826-2835; b) P. Thuéry, J. Harrowfield, Cryst. Growth Des. 2017, 17, 2116-2130; c) P. Thuéry, Y. Atoini, J. Harrowfield, Cryst. Growth Des. 2018, 18, 2609-2619; d) P. Thuéry, Y. Atoini, J. Harrowfield, Inorg. Chem. 2019, 58, 870-880.

[31] P. Thuéry, Y. Atoini, J. Harrowfield, Inorg. Chem. 2019, 58, 6550-6564.

[32] a) J. Xie, Y. Wang, W. Liu, X. Lin, L. Chen, Y. Zou, J. Diwu, Z. Chai, T. E. Albrecht-Schmitt, G. Liu, S. Wang, Angew. Chem. Int. Ed. 2017, 56, 7500-7504; b) Y. Wang, X. Yin, W. Liu, J. Xie, J. Chen, M. A. Silver, D. Sheng, L. Chen, J. Diwu, N. Liu, Z. Chai, T. E. Albrecht-Schmitt, S. Wang, Angew. Chem. Int. Ed. 2018, 57, 7883-7887.

[33] a) Y. Wang, Z. Liu, Y. Li, Z. Bai, W. Liu, Y. Wang, X. Xu, C. Xiao, D. Sheng, J. Diwu, J. Su, Z. Chai, T. E. Albrecht-Schmitt, S. Wang, J. Am. Chem. Soc. 2015, 137, 6144-6147; b) Z. Bai, Y. Wang, Y. Li, W. Liu, L. Chen, D. Sheng, J. Diwu, Z. Chai, T. E. Albrecht-Schmitt, S. Wang, Inorg. Chem. 2016, 55, 6358-6360.

[34] R. W. W. Hooft, COLLECT, Nonius BV: Delft, The Netherlands, 1998.

[35] Z. Otwinowski, W. Minor, Methods Enzymol. 1997, 276, 307-326.

[36] G. M. Sheldrick, Acta Crystallogr., Sect. A 2015, 71, 3-8.

[37] G. M. Sheldrick, Acta Crystallogr., Sect. C 2015, 71, 3-8.

[38] C. B. Hübschle, G. M. Sheldrick, B. Dittrich, J. Appl. Crystallogr. 2011, 44, 1281-1284. 
[39] L. J. Farrugia, J. Appl. Crystallogr. 2012, 45, 849-854.

[40] K. Momma, F. Izumi, J. Appl. Crystallogr. 2011, 44, 1272-1276.

[41] V. A. Blatov, A. P. Shevchenko, D. M. Proserpio, Cryst. Growth Des. 2014, 14, 3576-3586.

[42] A. L. Spek, Acta Crystallogr., Sect. C 2015, 71, 9-18. 


\section{1,3-Adamantanedicarboxylate and 1,3-Adamantanediacetate as Uranyl lon Linkers: Effect of Counterions, Solvents and Differences in Flexibility}

Key Topic: Uranyl Complexes

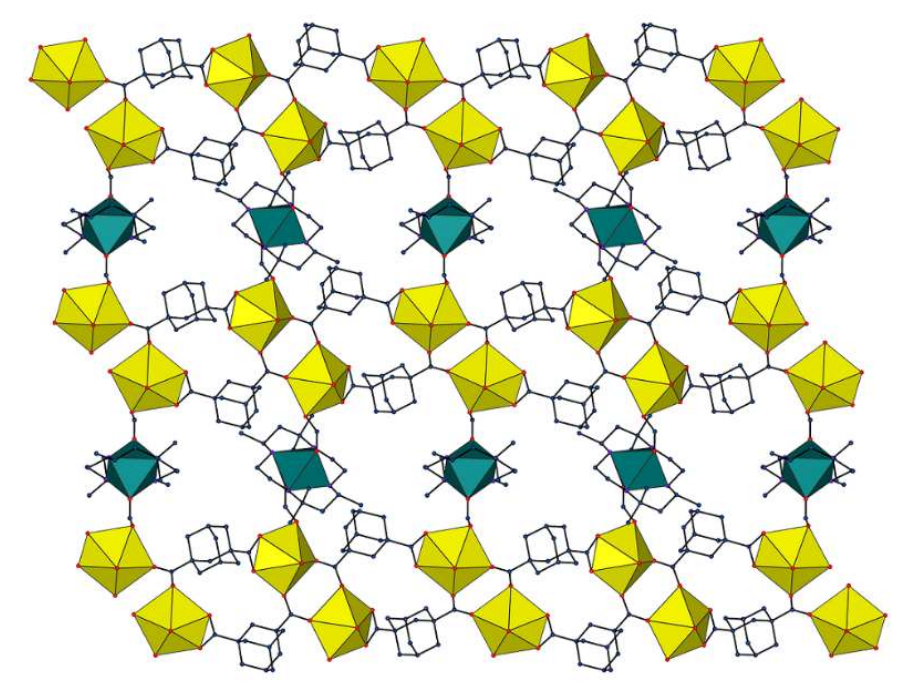

Mono- and diperiodic coordination polymers were obtained from uranyl complexation with 1,3adamantanedicarboxylate or 1,3-adamantanediacetate under solvo-hydrothermal conditions in the presence of various counterions and organic cosolvents. Several monoperiodic species assume a trough-like shape accommodating the counterions, while heterometallic diperiodic networks are formed through bridging of monoperiodic subunits by nickel(II) cations. 